\title{
(Re)visitando la Florencia del Renacimiento
}

(Re) visiting the Renaissance Florence

José Manuel Leiva Aldea

Graduado en Historia del Arte. Universidad de Málaga, España (joseleivaaldea@uma.es)

Recibido el 14 de febrero de 2018; revisado el 15 de marzo de 2018; aceptado el 24 de mayo de 2018; publicado el 12 de julio de 2018

RESUMEN: Assassin 's Creed es una de las franquicias más exitosas de los últimos años en el ámbito de los videojuegos. En las siguientes líneas analizaremos su relación con la recreación de períodos histórico-artísticos determinados. En ese caso pondremos nuestra mirada en la Italia del Renacimiento, concretamente durante la segunda mitad del s. XV en Florencia. Haremos un análisis de los distintos hitos artísticos producidos en la capital de la Toscana, de los personajes más relevantes del momento y de las diversas intrigas políticas que acaecieron en Florencia, cuna del Renacimiento.

PALABRAS CLAVE: Renacimiento, Florencia, Italia, Videojuegos, Assassin's Creed, Historia, Arte

\begin{abstract}
Assassin's Creed is one of the most successful franchises in recent years in the videogames sector. In the next lines we will analyze its relationship with the recreation of specific historical-artistic periods. In this specific case we look at the Italy of the Renaissance, specifically in Florence during the second half of the $15^{\text {th }}$ century. We will make an analysis of the different artistic landmarks produced in the capital of Tuscany, the most relevant characters of the moment and the various political intrigues that occurred in Florence, cradle of the Renaissance.
\end{abstract}

KEYWORDS: Renaissance, Florence, Italy, Videogames, Assassin's Creed, History, Art 


\section{Introducción}

En la Historia del Arte hay campos de estudio que aparentemente están totalmente analizados, caso del Quattrocento y Cinquecento italianos, entre otros. No obstante, las nuevas producciones de la Cultura Visual en el s. XXI, en las que destacamos especialmente al videojuego, están aportando nuevos sectores para las investigaciones científicas con el que estudiar y re-visionar diversos periodos histórico-artísticos. Gracias principalmente a los estudiantes más jóvenes, se elaboran trabajos de investigación en el ámbito universitario en el que indagan sobre cuestiones artísticas que atañen al videojuego. Esta investigación parte del interés en abarcar uno de los videojuegos que más importancia le han dado a la Historia y al Arte, Assassin's Creed, centrándonos en el caso de Assassin's Creed II, en el que se recrea la vida de distintas ciudades italianas del Renacimiento, destacando Florencia. Del tema seleccionado hay que decir que aún son escasas las publicaciones en lengua castellana, tanto divulgativas como científicas. En el mejor de los casos encontramos algún capítulo de libro en inglés, destacando el de Douglas N. Dow sobre la simulación histórica en Assassin's Creed II (Dow, 2003: 215-231). Sí que han proliferado numerosos artículos en blogs, fansites como Assassin's Creed Wiki o vídeos en YouTube, pero pueden ser interesantes como complemento para la investigación, carecen de rigor científico en la mayoría de las ocasiones.

\section{¿El videojuego?}

La RAE define el término videojuego como "juego electrónico que se visualiza en una pantalla" 1 . Consideramos incompleta dicha definición, ya que se omite la característica principal del producto, la interacción del usuario con lo visualizado, sobre todo en videojuegos open world o de mundoabierto, en los que el jugador puede moverse libremente e interactuar con el mapa o del mismo, que suele ser de grandes dimensiones, como el caso de Florencia en Assassin's Creed II. Esta interacción genera un feedback entre el mundo virtual y el real (el jugador, a través de unos intermediarios, la pantalla y la consola, recibe la tarea de completar una serie de misiones dentro del escenario virtual del videojuego, que irá superando con su respectivo personaje). Hoy en día, la industria de los videojuegos es la más rentable dentro del ámbito del ocio/entretenimiento a nivel global, superando incluso al cine y la

\footnotetext{
${ }^{1} \mathrm{http}: / /$ dle.rae.es/srv/search?m=30\&w=videojuego (Consultado: $\left.13 / 2 / 2018\right)$
} 
música, con ingresos de unos 110.000 millones de dólares en $2017^{2}$. El éxito de los videojuegos modernos se encuentra principalmente en el hecho de ser macro-producciones con presupuestos desorbitados al estilo del blockbuster cinematográfico. El desarrollo suele durar varios años, de ahí que los resultados sean muy satisfactorios. Un caso paradigmático es el del juego Grand Theft Auto $V$ (Rockstar Games, 2013), producido entre 2009-2013 con un presupuesto de 210 millones de dólares. Solo en el día de su lanzamiento se lograron unos 815 millones de dólares en venta a nivel global.

\section{¿Videojuegos y arte?}

El compositor de ópera alemán Richard Wagner acuñó a mediados del s. XIX el término de Gesamtkunstwerk, traducido al castellano como obra de arte total (Toman, 2006: 12). Referido inicialmente al mundo del teatro, Wagner hablaba de una obra de arte que, en el futuro, integraría a todas las artes independientes en una sola. En su caso, las obras teatrales integrarían música, pintura, escenografía y poesía, favoreciendo la experiencia multisensorial. La invención del cinematógrafo en 1895 y posteriormente el cine sonoro reafirmó la teoría de Wagner del arte del futuro como obra de arte total. Las producciones cinematográficas incluirían fotografía, imagen en movimiento, sonido y guion narrativo. Pero será con la aparición del videojuego cuando esta definición de la Gesamtkunstwerk llegue a su máxima expresión. A partir de dicho momento, el usuario, además de contar con estas experiencias multi-sensoriales a las que se ha hecho mención, podrá interactuar con el entorno del videojuego, influyendo cada una de sus acciones en el discurrir de la trama de este. A modo de creación neo-barroca, el discurso retórico del videojuego presenta una doble vertiente de interacción del jugador real y su personaje (Calabrese, 2005: 116-119).

\section{Recreación histórica}

Al igual que en literatura o cinematografía, uno de los géneros más frecuentes y exitosos del videojuego ha sido el histórico. A través de sagas antológicas como Total War (The Creative Assembly) o Age of Empires (Ensemble Studios), el usuario ha podido vivir distintos momentos fundamentales de la historia universal, dirigiendo legiones romanas, empuñando la espada de un soldado cruzado en Tierra Santa o defendiendo Constantinopla del asedio de los otomanos. Con esta recreación, la persona del s. XXI es capaz de presenciar acontecimientos pasados que nunca podrá ver,

\footnotetext{
${ }^{2}$ Datos obtenidos del artículo http://mobilemarketingmagazine.com/big-brands-can-learn-mobile-games-marketers (Consultado 13-2-2018)
} 
pero gracias a este simulacro puede hacerlo. Es por ello por lo que dentro de este ámbito del videojuego histórico hayan surgido opiniones críticas con el mismo, ya que es frecuente que la historia se cuente de manera fragmentada o con algunos toques de ficción, lamentando esa supuesta carencia de rigor histórico. Consideramos que esa pretensión no debería circunscribirse al sector de los videojuegos históricos. Bien es cierto que los productores y desarrolladores se toman licencias, pero su objetivo principal no es el de hacer una reconstrucción histórica fidedigna, sino el de crear una imagen de verosimilitud con la que podamos hacer una aproximación medianamente adecuada a las características principales del período histórico en cuestión. Y es que los videojuegos son simulacros, es decir, imágenes creadas mediante trucos visuales conscientes del juego y el artificio, por lo que no pretenden engañar (Baudrillard, 1993: 34).

\section{Franquicia Assassin's Creed}

Assassin's Creed es una franquicia trans-media ${ }^{3}$ creada por Ubisoft Montréal. Es la subsidiaria canadiense de la francesa Ubisoft Entertainment, fundada en 1986 (Brittany, Francia). Además del que trataremos, la compañía ha publicado otras series de videojuegos con gran impacto a nivel internacional, como Prince of Persia (1989), Rayman (1995) o Tom Clancy's (2000). La aparición de $A C$ (acróstico con el que se conoce popularmente a Assassin's Creed) en el mercado tuvo lugar el 13 de noviembre de 2007, coincidiendo con el lanzamiento de Assassin's Creed, primer videojuego de la compañía canadiense. La trama de este se desarrolla en la Tercera Cruzada (1191), en la que encarnamos a Altaïr Ibn-La'Ahad, miembro de la Hermandad de los Asesinos, con el que el jugador hará frente a la Orden de los Templarios en diversas ciudades de Oriente Próximo (Jerusalén, Damasco, Acre...). La acogida fue muy positiva, habiéndose vendido unas 11 millones de unidades hasta la fecha 4 . Posteriormente se han publicado nuevos títulos en los que visitamos nuevas épocas y localizaciones (Constantinopla, Revolución Americana, Revolución Francesa, Londres Victoriano o Egipto Ptolemaico, entre otros).

${ }^{3}$ Producción o creación de líneas narrativas a través de distintos canales de comunicación

${ }^{4}$ Datos obtenidos de la web http://www.vgchartz.com/game/12728/assassins-creed/?region=All (Consultado 13-2-2018) 


\section{Assassin's Creed II}

Dos años después del éxito de Assassin's Creed, la compañía de Montreal decide dar un giro temporal en la historia de $A C$. El protagonista del presente será Desmond Miles, al que ya vimos en el primer videojuego, pero en esta ocasión se codifica su secuencia genética para encarnar la piel de un antepasado 300 años posterior a Altaïr, Ezio Auditore da Firenze. De la Tercera Cruzada pasamos a la República de Florencia, en el año de 1476. En los momentos iniciales del videojuego iremos viendo cómo los Auditores mantienen estrechos lazos de amistad con algunas de las personalidades más relevantes del Renacimiento Italiano, como Lorenzo de Medici, Leonardo da Vinci, y Girolamo Savonarola, entre otros. En el videojuego, además de Florencia, nuestro personaje visitará otras ciudades italianas (Venecia, Roma, Forlì, San Gimignano y Monteriggioni).

\section{Florencia}

La ciudad contaba con 60.000 habitantes en 1530, considerable para su época. Aunque no era una de las ciudades más pobladas de Europa, la capital toscana experimentó una de las transformaciones urbanísticas más importantes de Italia durante los siglos XV y XVI (Burke, 2015: 218). Es por ello por lo que en Assassin's Creed II será frecuente encontrarnos con calles en las que hay andamios, edificios en construcción, artistas realizando pinturas murales y obreros finalizando algunos de los monumentos mayor envergadura, transmitiendo la idea de Florencia como ciudad en continuo desarrollo [1]. En el entramado urbano de la Florencia de $A C I I$ nos encontraremos con una serie de establecimientos en los que podemos adquirir obras capitales del Renacimiento Italiano (realizadas en esa fecha o posteriores al momento en el que estemos jugando). Entre los autores de estas piezas hay algunas de Piero della Francesco, Botticelli, Leonardo, Rafael y Tiziano, entre otros. Según Peter Burke, a partir del s. XV comenzó a difundirse este tipo de ventas de obras ya terminadas en las ciudades con mayor sensibilidad artística (Burke, 2015: 124-126).

Al igual que sucede con otras ciudades medievales de Europa, Florencia se cerraba perimetralmente con una muralla, conocida en italiano como L'Antica Cerchia. Construida ya en época romana, el perímetro de la urbe fue extendiéndose durante los siglos sucesivos, abriéndose nuevas puertas que delimitaban las diferentes salidas de la ciudad. El trazado visual de esta muralla lo 
conocemos gracias a algunos dibujos y pinturas realizados durante la Edad Moderna. A mediados del s. XIX, fruto de las ampliaciones urbanísticas de la ciudad, gran parte de estos lienzos de muralla se derruyeron. En $A C I I$ se ha hecho una recreación a pequeña escala de lo que es la cerca, con sus respectivas puertas, pudiendo visualizarla desde los puntos más altos de la ciudad.

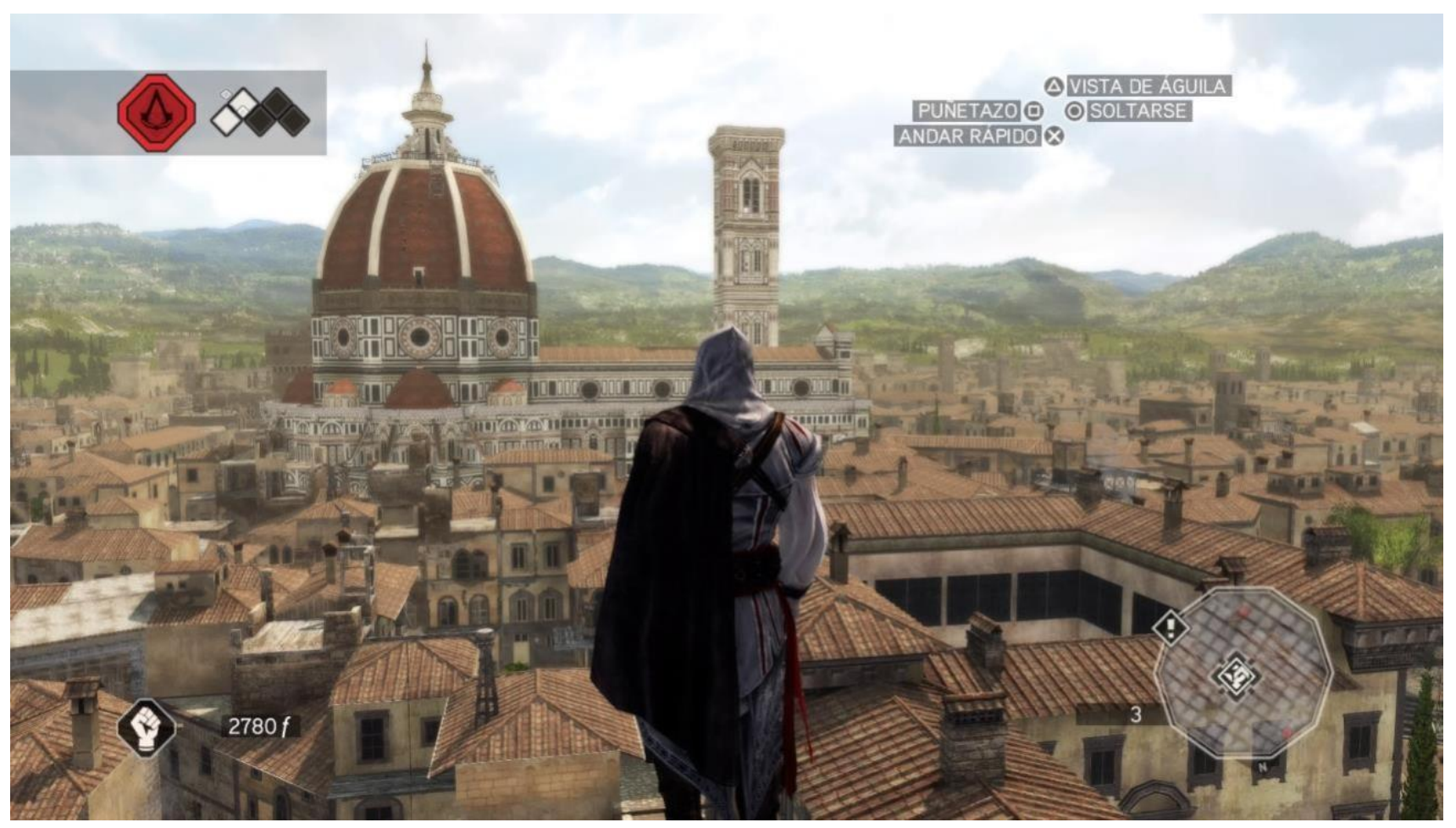

1. Panorámica de Florencia con especial detalle en el Duomo.

\section{Cattedrale di Santa Maria del Fiore}

También conocida como Il Duomo, es una de las construcciones emblemáticas de Italia [2]. La actual iglesia gótica, proyectada por Arnolfo di Cambio, entre otros, se levanta sobre un antiguo templo paleocristiano consagrado a Santa Reparata. Llegados al s. XV nos encontramos con una iglesia sin terminar, a la que le falta la cúpula, por lo que el arquitecto Filippo Brunelleschi presenta su proyecto para finalizar este edificio emblemático. La construcción de este icono tiene lugar entre 1420-1436, con la colocación final de la linterna en 1471, símbolo de la hegemonía florentina (VV.AA., 2012: 166). En ACII, nos encontraremos con la cúpula y linterna ya finalizadas (estamos en el año de 1476). Tanto la cúpula como el interior se han recreado a una escala mucho menor de la real para poder recorrer sus distintas partes sin que esto afecte a nuestro personaje, además de la complejidad técnica que este proceso requiso en 2009. En cuanto a las calidades cromáticas y texturas, la reproducción se 
ha hecho es excelente. La fachada principal de la catedral fue diseñada por Arnolfo di Cambio en el s. XIV, aunque nunca llegó a concluirse. En el videojuego se ha optado por hacer una recreación más libre que con el resto del edificio. La actual es de finales del s. XIX. La visión que tenemos en se toma licencias históricas, pero no artísticas, ya que se nos presenta como si el frontis del s. XIX en construcción a finales del s. XV. También hay que destacar la recreación que se ha hecho del interior del edificio, que nos da una idea bastante acertada de cómo es en la realidad, sobre todo en lo relativo a iluminación.

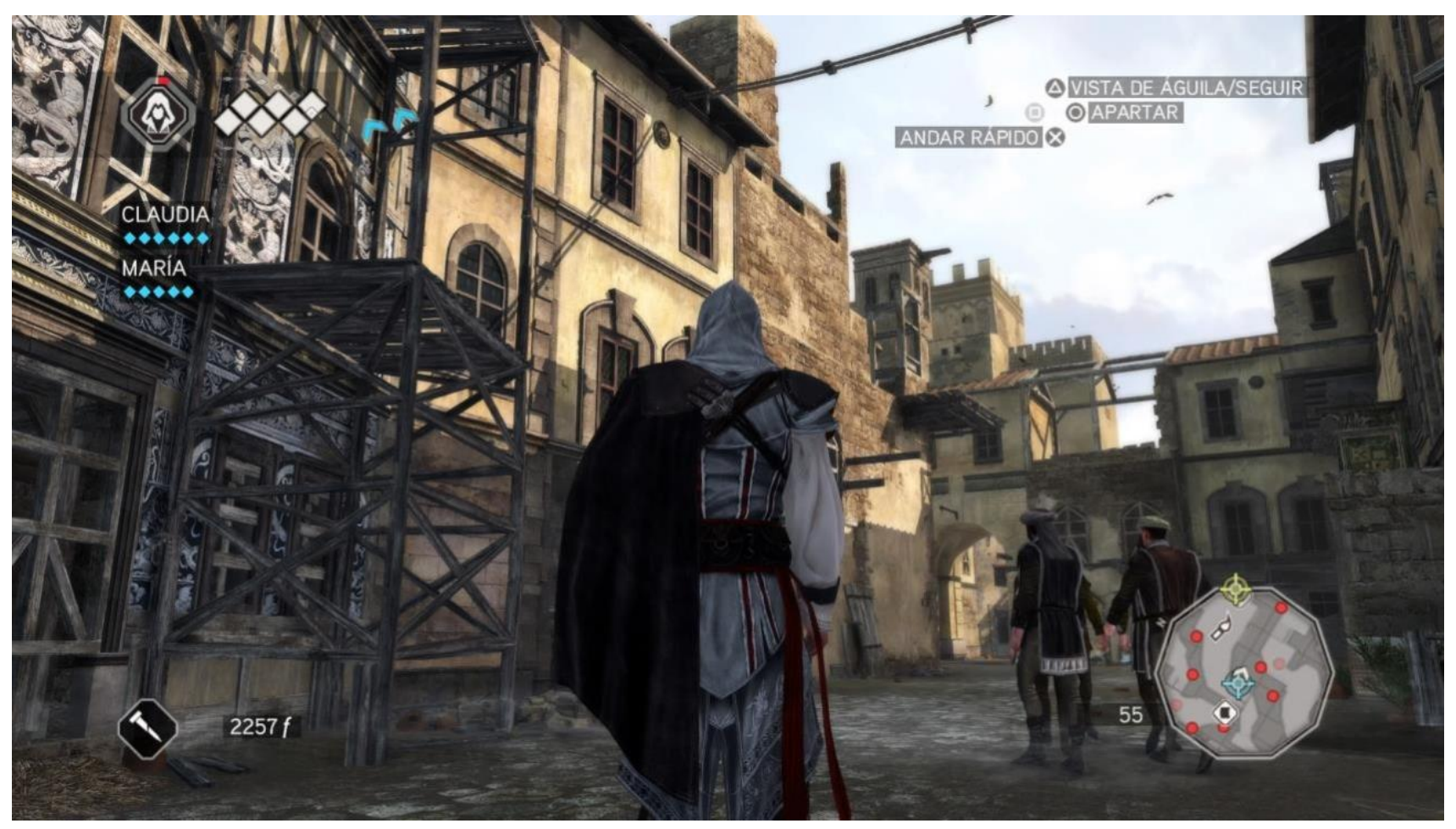

2. Las calles de Florencia nos dan sensación de cambio y renovación urbanística

\section{Ponte Vecchio}

Reconstruido en el s. XIV sobre otros anteriores de época medieval, es otro de los puntos principales de la ciudad [3]. Durante la Edad Media y parte del s. XV, concentró buena parte de las carnicerías Florencia, pero ya a finales del s. XVI se reconvierten en joyerías por el mal olor que desprendían estas tiendas. El puente que podemos ver en el videojuego es prácticamente idéntico al de la realidad, aunque el cuerpo superior, parte del trazado del Corridoio Vasariano, se realizó ya en el s. XVI. Además, se 
ha incidido en la función que tenía en la época, con numerosos negocios, confiriéndole la impronta de zona de comercio que debió tener.

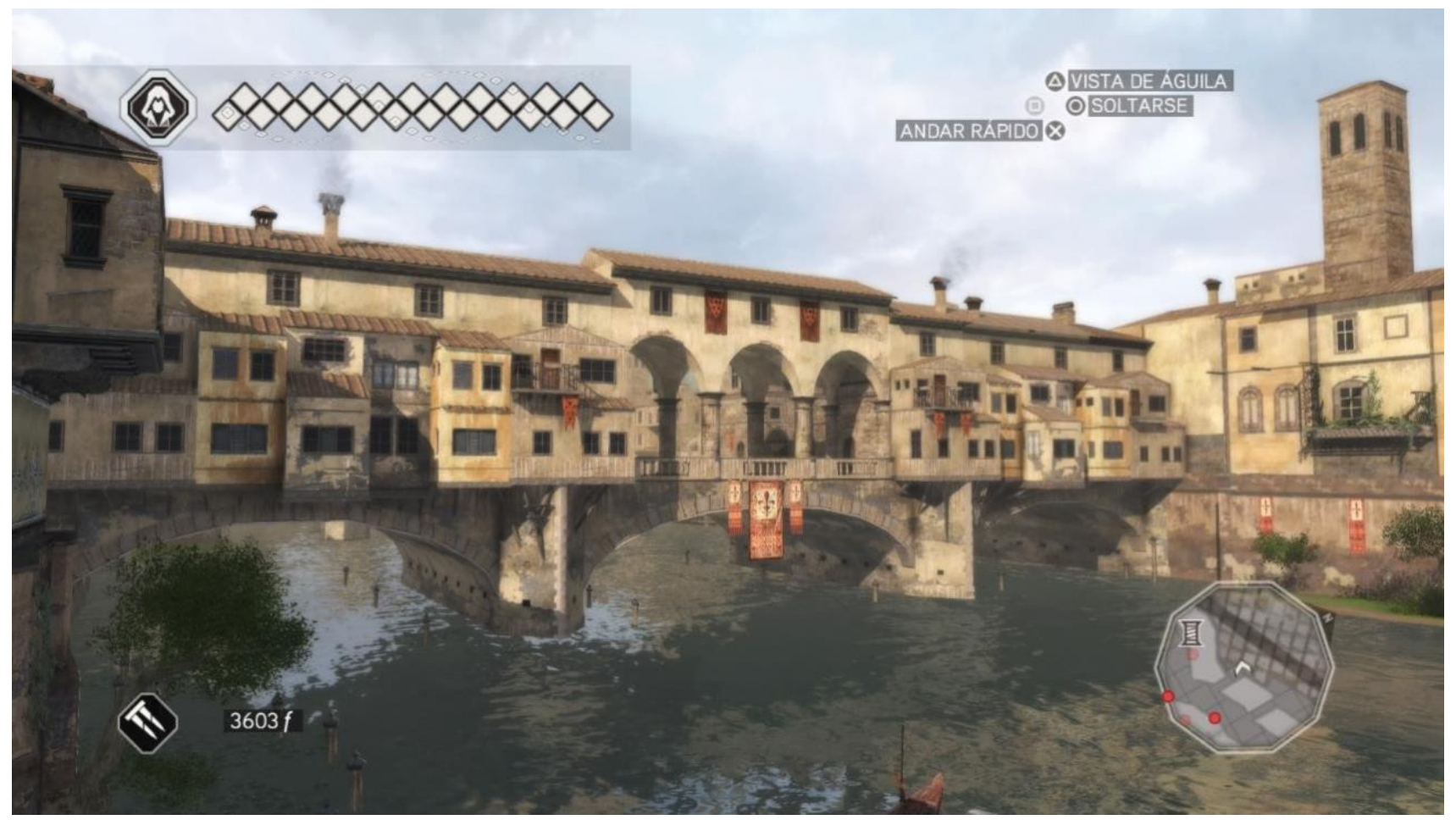

3. El turístico Ponte Vecchio es uno de los puntos más importantes del videojuego

\section{Palazzo Pitti}

Mandado construir inicialmente por la familia Pitti, no se sabe aún con certeza su autoría. El aspecto actual de la fachada del palacio corresponde a las reformas tardo-barrocas del s. XVII, con la gran ampliación de las alas laterales y los cuerpos de la fachada, siguiendo la línea del almohadillado florentino, iniciado en el Palazzo Medici. Fue utilizado como residencia por los Medici desde mediados del s. XVI. y posteriormente por los Lorena y Saboya. Tras él se dispone el Giardino di Boboli, uno de los jardines históricos más interesantes de Italia. En el videojuego se ha recreado el palacio tal y como lo vemos en la actualidad, incluyéndose la ampliación de la fachada del s. XVII y las alas laterales del s. XVIII. Aun recreándose a escala menor que el modelo real, nos da una idea su gran tamaño. 


\section{Basilica di Santa Maria Novella}

Construida en época medieval, es la principal iglesia de la Orden de los Predicadores (Dominicos) en Florencia. La fachada no se culmina hasta 1470, diseñada por el teórico y arquitecto Leon Battista Alberti, haciendo de ella otro de los símbolos de la ciudad. Sobre el campanile, realizado durante els. XIV, tenemos constancia gráfica desde el s. XVI, como podemos ver en la célebre Pianta del Buonsignori. En Assassin's Creed II, la iglesia dominica es uno de los edificios que mejor se han recreado, destacando su portada, el cuerpo externo de las naves del templo y la torre campanario, respetando sus proporciones de una forma asombrosa [4]. No obstante, tanto la plaza en la que se ubica no tiene ningún parecido con la realidad, y la estatua del Apolo del Belvedere que hay en el centro de esta no se descubre hasta 1498.

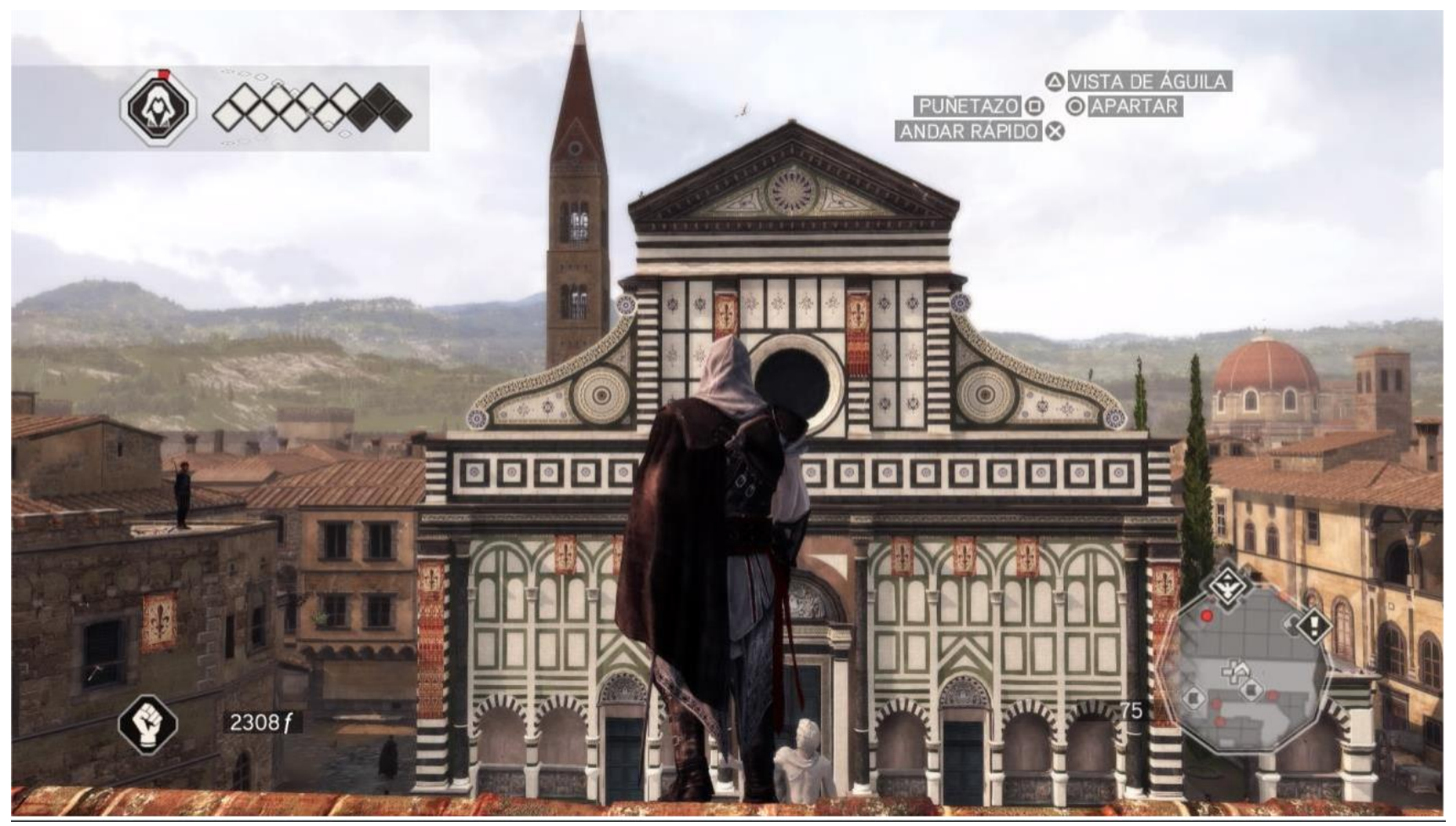

4. Reconstrucción casi idéntica de la fachada de Santa Maria Novella

\section{Palazzo Medici}

Encargo de Cosimo Il Vecchio es el edificio que sirve de modelo, junto al Palazzo Rucellai, para el resto de los palacios en Florencia y otras ciudades italianas. Se sitúa en la antigua Via Larga, a escasos 
metros del Duomo y San Lorenzo, en una ubicación muy destacada que da cuentas del poder de los Medici en el s. XV. En su interior hay un claustro de planta cuadrada, con la típica bicromía blancopietra serena tan habitual en las construcciones florentinas del s. XV, junto a una serie de relieves, blasones y pintura mural en el friso que hay sobre las arcadas (Zoppi y Donati, 1997: 77-79). Las crónicas de la época cuentan que el célebre David de Donatello fue colocado en el centro de este claustro (1495), previamente sito en el jardín del palacio (Paolucci, 2012: 140). En ACII tendremos la posibilidad de contemplar tanto la fachada, recreada a escala menor que la real y manteniendo los elementos más representativos de la misma: heráldica Medici, cornisa, ventanas bíforas... como el patio del palacio. [5].

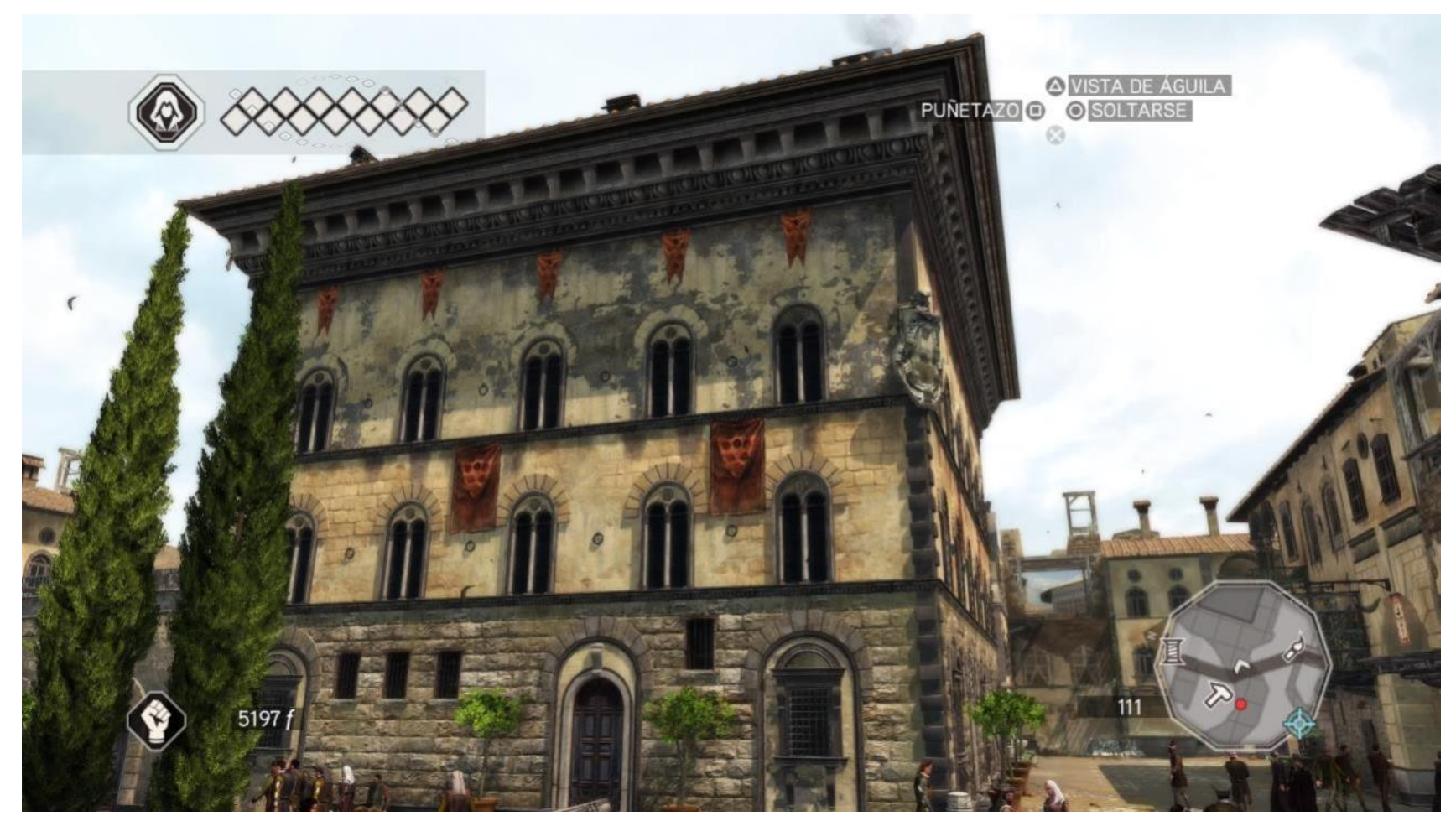

5. Vista del Palazzo Medici, uno de los palacios claves dentro del Renacimiento Italiano

\section{Conclusiones}

En primer lugar, consideramos que urge la necesidad de considerar definitivamente al videojuego como arte dentro del ámbito académico en nuestro país, de ahí que aún sean escasas las publicaciones científicas sobre este tema. Por ello, se hace necesaria la consulta de fuentes anglosajonas. Partimos de la base etimológica de la misma palabra arte procedente del latín ars y del griego $\tau \varepsilon ́ \chi v \eta$. Estos 
términos se han traducido al español como la capacidad humana de crear, basados en lo real o lo imaginario, manifestándose sensorialmente Consecuentemente, creemos que no es atrevida la calificación del videojuego como arte, ya que cumple sobradamente estos requisitos. Además, en el videojuego, al igual que en el cine, literatura o la pintura, se establece una línea narrativa, por lo que también lo consideramos como arte. En segundo lugar, manifestamos nuestra satisfacción con este estudio de Cultura Visual en cuanto que permite aportar nuevos puntos de vista sobre períodos emblemáticos de la Historia del Arte, el Renacimiento en nuestro caso. En tercer lugar, pensamos que no se puede pretender la recreación $100 \%$ real de los hitos y monumentos representados en ACII. Éste es un simulacro que se inspira de lo real dándonos algunas de las claves básicas para entender qué fue la cultura del Quattrocento en Florencia. Esta condición solo deberíamos de aplicarla a estudios científicos o académicos. Por último, estamos convencidos de que este estudio abrirá las puertas a futuras investigaciones en torno a la relación del videojuego con la Historia del Arte. En ellas analizaríamos otras ciudades y períodos históricos recreados en Assassin's Creed, tales como Egipto Ptolemaico, las Cruzadas, la Revolución Francesa o el Londres Victoriano, entre otros.

\section{Referencias bibliográficas}

- BAUDRILLARD, Jean. (1993), Cultura y Simulacro. Barcelona, Editorial Kairós.

- BURKE, Peter. (2015), El Renacimiento italiano. Cultura y Sociedad en Italia. Madrid, Alianza Editorial.

- CALABRESE, Omar. (2005), 'Otras inestabilidades: Los videojuegos', en La Era Neobarroca. Madrid, Ediciones Cátedra.

- DOW, N. Douglas. (2013), 'Historical Veneers: Anachronism, Simulation, and Art History in Assassin's Creed II', en WILHELM, M. y ELLIOT, A., (ed.), Playing with the Past. Londres, Bloomsbury Publishing.

- PAOLUCCI, Antonio. (2012), Donatello. Milán, Skiera Editore.

- TOMAN, Ralf. (ed.) (2006), Neoclasicismo y Romanticismo. Barcelona, Edit. H.f.ullmann.

- VV.AA. (2012), Florencia. Arte y Arquitectura. Barcelona, Edit. H.f.ullmann, 2012

- ZOPPI, Mariella y DONATI, Cristina (1997), Guida ai Chiostri e Cortili di Firenze. Florencia, Alinea Editrice.

- http://dle.rae.es/srv/search?m=30\&w=videojuego (Consultado: 13/2/2018) 
- http://mobilemarketingmagazine.com/big-brands-can-learn-mobile-gamesmarketers

(Consultado: 13/2/2018)

- http://www.vgchartz.com/game/12728/assassins-creed/?region=All (Consultado: 13/2/2018) 